\title{
Post-Retained Single Crowns versus Fixed Dental Prostheses: A 7-Year Prospective Clinical Study
}

Journal of Dental Research 2017, Vol. 96(I3) 1490-1497

(C) International \& American Associations for Dental Research 2017

Reprints and permissions: sagepub.com/journalsPermissions.nav DOI: $\mid 0.1$ I 77/00220345I7724|46 journals.sagepub.com/home/jdr

\author{
M. Ferrari ${ }^{1,2}$, R. Sorrentino ${ }^{1,3}$, J. Juloski, ${ }^{1,4}$, S. Grandini ${ }^{5}$, M. Carrabba', \\ N. Discepoli ${ }^{6}$, and E. Ferrari Cagidiaco ${ }^{7}$
}

\begin{abstract}
Biomechanical integrity of endodontically treated teeth (ETT) is often compromised. Degree of hard tissue loss and type of final prosthetic restoration should be carefully considered when making a treatment plan. The objective of this prospective clinical trial was to assess the influence of the type of prosthetic restoration as well as the degree of hard tissue loss on 7-y clinical performance of ETT restored with fiber posts. Two groups $(n=60)$ were defined depending on the type of prosthetic restoration needed: I) single unit porcelain-fused-to-metal (PFM) crowns (SCs) and 2) 3- to 4-unit PFM fixed dental prostheses (FDPs), with I healthy and I endodontically treated and fiber post-restored abutment. Within each group, samples were divided into 2 subgroups $(n=30)$ according to the amount of residual coronal tissues after abutment buildup and final preparation: A) $>50 \%$ of coronal residual structure or $B$ ) equal to or $<50 \%$ of coronal residual structure. The clinical outcome was assessed based on clinical and intraoral radiographic examinations at the recalls after 6, 12, 24, 36, 48, and 84 mo. Data were analyzed by Kaplan-Meier log-rank test and Cox regression analysis $(P<0.05)$. The overall 7-y survival rate of ETT restored with fiber post and either SCs or FDPs was $69.2 \%$. The highest 84 -mo survival rate was recorded in group IA $(90 \%)$, whereas teeth in group $2 B$ exhibited the lowest performance $(56.7 \%$ survival rate). The log-rank test detected statistically significant differences in survival rates among the groups $(P=0.048)$. Cox regression analysis revealed that the amount of residual coronal structure $(P=0.04 \mathrm{I}$; hazard ratio $[\mathrm{HR}], 2.026 ; 95 \%$ confidence interval $[\mathrm{Cl}]$ for $\mathrm{HR}, \mathrm{I} .03 \mathrm{I}-3.982)$ and the interaction between the type of prosthetic restoration and the amount of residual coronal structure $(P=0.024 ; \mathrm{HR}, 1.372 ; 95 \% \mathrm{Cl}$ for $\mathrm{HR}, \mathrm{I} .042-$ I.806) were statistically significant factors for survival (ClinicalTrials.gov NCTOI532947).
\end{abstract}

Keywords: endodontics, prosthetic dentistry/prosthodontics, clinical trial, dental restoration failure, dental prosthesis, dental bonding

\section{Introduction}

The use of fiber-reinforced composite posts (i.e., fiber posts) for restoring endodontically treated teeth (ETT) has been extensively investigated (Schwartz and Robbins 2004; Peroz et al. 2005). Favorable physical properties and optimal biocompatibility were reported as the main advantages of fiber posts (Tay and Pashley 2007; Dietschi et al. 2008; Goracci and Ferrari 2011). However, as biomechanical integrity is compromised, making optimal treatment planning for restoration of ETT may be difficult.

The amount of remaining sound coronal tissues is considered very important for the clinical performance. Preservation of at least a 2-mm ferrule contributes to tooth mechanical resistance and is considered one of the key factors affecting tooth longevity (Stankiewicz and Wilson 2002; Jotkowitz and Samet 2010; Juloski et al. 2012; Juloski, Apicella, et al. 2014). Clinical studies have been conducted specifically aiming at revealing the influence of the degree of hard tissue loss on the survival of ETT restored with fiber posts (Mancebo et al. 2010; Signore et al. 2011; Ferrari et al. 2012; Juloski, Fadda, et al. 2014). Although the results showed satisfactory overall survival rates, a higher occurrence of failures was recorded in teeth with a higher degree of tissue loss (Mancebo et al. 2010; Signore et al. 2011; Ferrari et al. 2012; Juloski, Fadda, et al. 2014).

Moreover, in all abovementioned studies, teeth were restored with fiber posts and full porcelain-fused-to-metal (PFM) or all-ceramic crowns. However, the influence of the

'Department of Medical Biotechnologies, Division of Fixed Prosthodontics, University of Siena, Siena, Italy

${ }^{2}$ Department of Restorative Dentistry, University of Leeds, Leeds, UK ${ }^{3}$ Department of Neurosciences, Reproductive and

Odontostomatological Sciences, University Federico II, Naples, Italy

${ }^{4}$ Clinic for Paediatric and Preventive Dentistry, Faculty of Dental

Medicine, University of Belgrade, Serbia

${ }^{5}$ Department of Medical Biotechnologies, Division of Restorative Dentistry and Endodontics, University of Siena, Siena, Italy

${ }^{6}$ Department of Medical Biotechnologies, Division of Periodontics, University of Siena, Siena, Italy

${ }^{7}$ Department of Medical Biotechnologies, Division of Periodontics, Complutense University, Madrid, Spain

\section{Corresponding Author:}

M. Ferrari, Department of Medical Biotechnologies, Division of Fixed Prosthodontics, University of Siena, Policlinico Le Scotte, viale Bracci, Siena 53100, Italy.

Email: ferrarm@gmail.com 
type of the final prosthetic restoration on the clinical performance must be considered. Also, care should be taken to make optimal treatment planning, in terms of occlusal loads and parafunctional stresses the restored tooth might be exposed to. It was reported that position of teeth (Naumann, Blankenstein, Kiessling, et al. 2005; Schmitter et al. 2007; Schmitter et al. 2011) and presence of adjacent elements (Naumann, Blankenstein, Kiessling, et al. 2005; Naumann et al. 2008) were significant predictors of failure. Conversely, another study did not reveal any difference in clinical behavior among incisors, canines, premolars, and molars (Mancebo et al. 2010). Regarding the type of final restoration, an observational prospective clinical study reported that the type of final restoration represents a significant predictor for failure in fiber postretained restorations (Naumann, Blankenstein, Kiessling, et al. 2005). Nevertheless, a recently published review on randomized controlled trials (RCTs) confirmed that a univocal correlation between failure rates of fiber post-restored teeth and the type of prosthetic restoration (single crown or fixed dental prosthesis) cannot be found (Sorrentino et al. 2016).

Therefore, the aim of this prospective clinical study was to assess the 7-y clinical performance of ETT restored with fiber posts and single crowns (SCs) and compare it to that of fixed dental prostheses (FDPs) with 1 healthy and 1 endodontically treated and fiber post-restored abutment. A further aim was to investigate whether the degree of hard tissue loss of ETT affected the clinical outcome.

The null hypothesis tested was that neither the type of prosthetic restoration nor the amount of coronal tissues had a significant effect on the 7-y survival of ETT restored with fiber posts.

\section{Materials and Methods}

The protocol for this prospective clinical study was approved by the Institutional Review Board of the University of Siena, Italy. In total, 120 patients consecutively presenting at a private dental office for receiving endodontic treatment on teeth in posterior areas (premolars, first and second molars) that were subsequently prepared as abutments for SCs or 3- to 4-unit FDPs participated in the study.

After receiving clear information about the purpose of the trial, according to a preliminarily approved protocol, all patients provided written, informed consent before entering the study. The study population consisted of 53 males and 67 females (age range, 18-76 y; mean, $49 \mathrm{y}$ ). The following inclusion criteria were used: need of endodontic treatment on 1 of the premolars or molars with no signs of periapical lesions at baseline radiographs; need of at least $1 \mathrm{SC}$ or 3- to 4-unit FDP in posterior regions, with at least 1 endodontically treated abutment (premolar or molar); natural opposing dentition; natural agonist teeth; no untreated periodontal disease; and bone loss not $>3 \mathrm{~mm}$. The following exclusion criteria were adopted: patient age younger than $18 \mathrm{y}$; systematic diseases or severe medical complications; disabilities; pregnancy; periodontal disease; heavy occlusal contacts or history of bruxism; deep defects close to pulp $(<1 \mathrm{~mm}$ distance) or pulp capping on healthy, nonendodontically treated abutments of the FDPs; xerostomia; poor oral hygiene; plaque index higher than 20; lack of compliance; and language barriers. Regarding demographic data and clinical characteristics, all the experimental groups were homogeneous.

Two experimental groups $(n=60)$ were defined as follows, according to the type of prosthetic restoration needed by each patient:

Group 1 (SCs): Single-unit PFM SCs on endodontically treated and fiber post-restored abutments

Group 2 (FDPs): 3- to 4-unit PFM FDPs with 1 healthy and another endodontically treated and fiber post-restored abutment. All the FDPs were fabricated onto 2 abutments only, and no cantilevered pontics were included.

Two experimental subgroups $(n=30)$ were defined as follows, according to the amount of tissues left at the coronal level after endodontic treatment and abutment preparation:

Subgroup A (strong): More than 50\% of residual coronal structure, at least 2 sound walls, and a $1.5-\mathrm{mm}$ ferrule effect of the endodontically treated and fiber postrestored abutment

Subgroup B (weak): Equal to or $<50 \%$ of residual coronal structure, at least 1 sound wall, and a $1.5-\mathrm{mm}$ ferrule effect of the endodontically treated and fiber postrestored abutment

A "wall" was defined as a residual coronal structure of at least $3 \mathrm{~mm}$ in height. In the teeth with more than 1 root, only 1 post was placed.

The randomization was not possible in the present prospective clinical study, as the patients were assigned to the specific group based on their need for prosthetic rehabilitation and the current clinical situation.

\section{Clinical Procedures}

A single experienced operator with expertise in the fields of endodontics and prosthodontics performed the clinical procedures (Table 1). The crown preparation varied from a full chamfer with interproximal and lingual bevels to a featheredge finish line, depending on the height and thickness of the remaining structure. PFM SCs or FDPs were fabricated and luted with a glass-ionomer cement (Fuji Cem; GC Corp.).

\section{Evaluation Parameters}

The clinical outcome was assessed based on clinical and intraoral radiographic examinations at the recalls after $6,12,24,36$, 48, and 84 mo. Two blinded, well-trained examiners, other than the operator who had carried out the restorative treatment, were calibrated and performed evaluation of the outcome independently. The following events were recorded as failures: 1) post debonding, 2) post fracture, 3) vertical or horizontal root fracture, and 4) periapical lesions requiring endodontic 
Table I. Detail Description of Clinical Procedures Followed in Endodontic Treatment and Post Space Preparation and Cementation.

Endodontic treatment

- Canal instrumentation with K-files (8-10-15; Dentsply Maillefer) and Flexmaster rotary instruments (I5-20-25-30-35-40; VDW) mounted on the endodontic motor (Endo IT professional; Aseptico) to a working length of $0.5 \mathrm{~mm}$ from the apex

- Irrigation with $5.25 \%$ sodium hypochlorite using a long 27 -gauge needle at each change of instrument

- Final rinse with deionized water and patency of the canal maintained with a No. 10 K-file

- Drying the canals with multiple paper points

- Obturation with gutta-percha using the continuous wave technique up to 4 to $5 \mathrm{~mm}$ from the apex with a System B heat source (SybronEndo)

- Backfilling of the canals using termoplastic gutta-percha from the Obtura II Unit (Obtura Corp.)

- Sealing the canal access with glass-ionomer cement (Fuji IX; GC Corp.)

Post space preparation

- Removing the temporary coronal seal at least $24 \mathrm{~h}$ after endodontic treatment

- Preparation of post spaces 7 to $8 \mathrm{~mm}$ in depth with precalibrated drills provided by the manufacturer (GC Corp.); at least $4 \mathrm{~mm}$ of intact apical seal left

- Choosing post size to fit best the diameter of the canal (diameter of the post $1.2 \mathrm{~mm}, 1.4 \mathrm{~mm}$ or $1.6 \mathrm{~mm}$ )

- Checking the fit of the post and shortening with a diamond bur to an adequate length

- Pretreating the post with a silane coupling agent (GC Ceramic Primer; GC Corp.)

Fiber post cementation

- Application of Self-Etching Bond (GC Corp.) by dispensing I drop of Bond Liquid A and B into the dispensing dish, mixed thoroughly for $5 \mathrm{~s}$ by means of the micro-tip applicator

- Application of the mixture inside the post space and on the residual coronal structure, left undisturbed for $30 \mathrm{~s}$, gently air-dried, and light-cured for $10 \mathrm{~s}$ with a visible light-curing unit (GC Light; GC Corp.)

- Gradia Core (GC Corp.) was dispensed into the prepared root canal through an Automix Endo tip

- Insertion of the post (GC Fiber Post; GC Corp.) and light curing (5 s) to fix its position temporarily

- The paste was dispensed around the post to form the core, light-curing from the vestibular and lingual sides ( $10 \mathrm{~s}$ each side) for final setting

retreatment. The absence of any apparent signs of clinical failure was selected as the criterion for survival.

The CONSORT (Consolidated Standards of Reporting Trials) flow diagram is reported in Figure 1.

\section{Statistical Analysis}

Survival rates were calculated by the nonparametric KaplanMeier survival analysis. The fiber post-retained restorations were defined as either surviving or not surviving according to the following criteria: survival was a positive, censored event, whereas nonsurvival was defined as the negative, uncensored event. The cementation of the final restorations was considered the analysis baseline. The end of observation for a failed restoration was when the failed restoration was detected during the follow-up appointments. The null hypothesis that there is no difference among the groups in the probability of failure was tested by means of the log-rank test.

In addition, the Cox regression analysis was used to assess the influence of the type of prosthetic restoration, the amount of residual coronal tooth structure, and the interaction between the 2 variables on the survival rate. To check that the proportional hazard ratio assumption was satisfied in the Cox regression model, we obtained the log-minus-log plot of survival for each variable and the lines' parallelism.

The level of significance was set at $P<0.05$ and statistical calculations were handled with SPSS Statistics software (SPSS, Inc.).

\section{Results}

Data were not affected by any loss at follow-up. The overall 7-y survival rate of ETT restored with fiber post and either SCs or FDPs was $69.2 \%$. Teeth with $>50 \%$ of coronal structure restored with SCs (group 1A) had the highest 84-mo survival rate $(90 \%)$. Conversely, the least satisfactory clinical performance was recorded for teeth with equal to or $<50 \%$ of coronal residual structure prepared as one of the abutments for FDPs (group 2B, survival rate 56.7\%). Table 2 reports survival rates after a 7 -y observation period in the experimental groups.

The Kaplan-Meier survival plot of cumulative survival of all 4 groups is presented in Figure 2A. The log-rank test determined that there were significant differences among the survival rates of the 4 groups $(P=0.048)$. Further pairwise comparisons of the survival rates were performed to detect between which 2 groups the differences were significant. Graphs representing the survival curves and results of the log-rank tests of pairwise comparisons are presented in Figure 2B-G.

The Cox regression analysis revealed that the type of prosthetic restoration did not have a significant influence on the restoration failure risk $(P=0.120$; hazard ratio [HR], 1.695; 95\% confidence interval [CI] for HR, 0.872-3.295). Conversely, the amount of coronal residual structure significantly influenced the restoration failure risk ( $P=0.041$; HR, 2.026; 95\% CI for HR, 1.031-3.982). The interaction between the 2 variables was also found to have a significant influence on the survival of fiber post-restored teeth $(P=0.024$; HR, $1.372 ; 95 \%$ CI for HR, 1.042-1.806).

The distribution of failure modes over the 7-y evaluation period among the groups is presented in Table 3 .

\section{Discussion}

The results of the present study indicate that the risk of failure in ETT restored with fiber posts was significantly influenced by the amount of coronal residual structure during $7 \mathrm{y}$ of clinical service. In addition, the survival analysis showed statistically significant differences among the groups. Therefore, the null hypothesis was rejected. 
The present study revealed the satisfactory overall 7-y survival rate of ETT in posterior regions restored with fiber posts and either SCs or FDPs $(69.2 \%$, regardless of the type of prosthetic restoration and the amount of hard tissue loss). These findings are in agreement with previously published studies (Ferrari et al. 2012; Sterzenbach et al. 2012; Juloski, Fadda, et al. 2014; Guldener et al. 2017) and reviews (Cagidiaco, Goracci, et al. 2008; Ploumaki et al. 2013) on the clinical performances of fiber post-restored teeth.

To our knowledge, this study is the first prospective study to report results on long-term performance of ETT restored with fiber posts and FDPs compared to SCs, and the results revealed significant differences in the survival rates. The highest survival rate was found in teeth with $>50 \%$ of tooth structure restored with SCs $(90.0 \%)$, while the lowest survival rate was recorded in teeth with $<50 \%$ of remaining tooth structure restored with FDPs (56.7\%). The log-rank test confirmed that significant differences existed in the survival curves between these 2 groups (Fig. 2F). Teeth from the remaining 2 groups exhibited similar survival rates (SCs and $<50 \%$ of tooth structure, $63.3 \%$; FDPs with $>50 \%$ of tooth structure, $66.7 \%$ ), with no significant differences (Fig. 2E).

Regardless of the type of prosthetic restoration, the survival of teeth in subgroup A was $78.3 \%$ and survival of teeth in subgroup B was $60 \%$ over $7 \mathrm{y}$. The

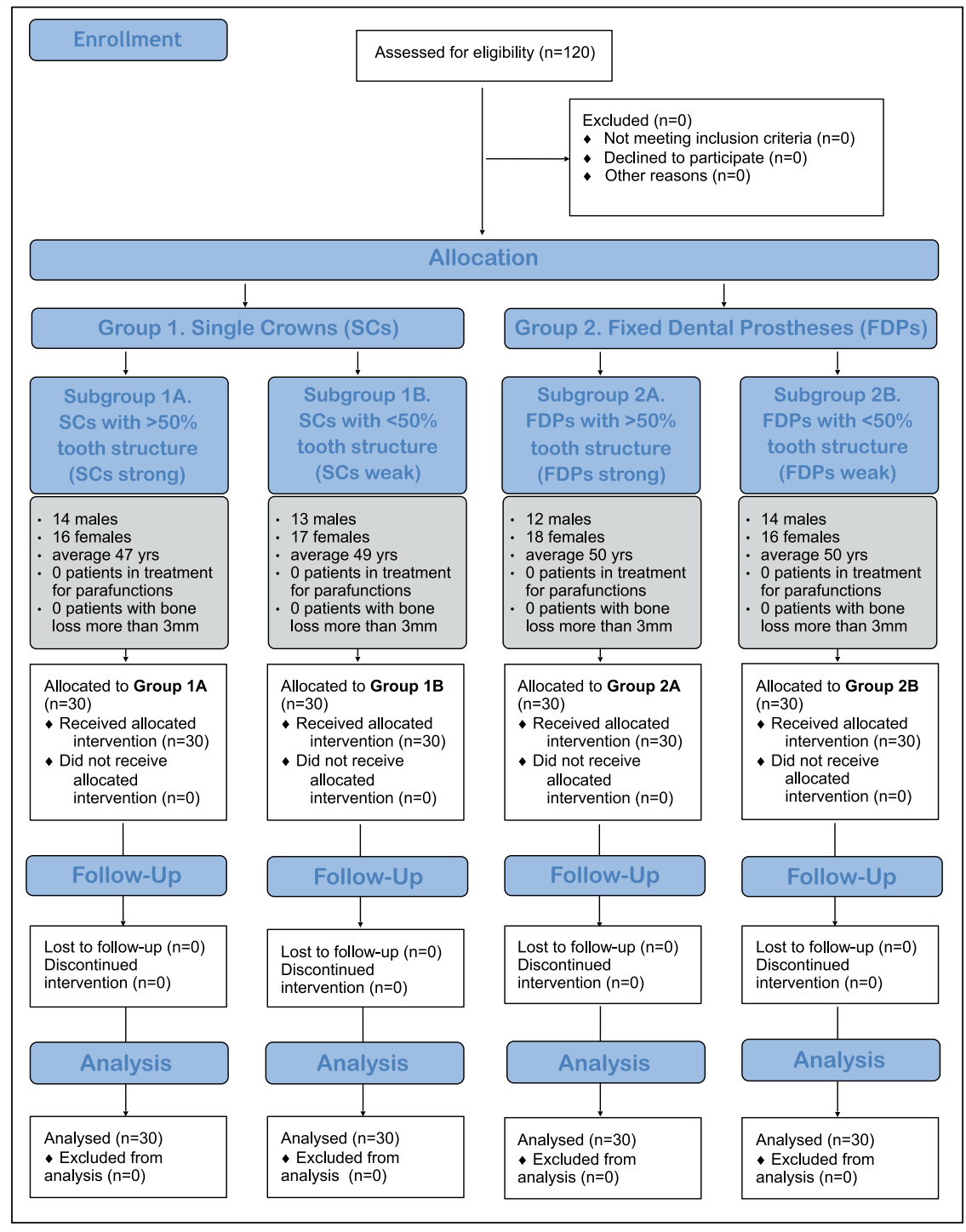

Figure I. CONSORT (Consolidated Standards of Reporting Trials) flow diagram.

\section{Cox regression analysis revealed that the}

degree of hard tissue loss was a significant risk factor associated with survival. Indeed, the HR indicates that prosthetic restorations placed on posterior teeth with a higher degree of tissue loss had a 2 times higher risk of failure (HR, 2.026) compared to teeth with more tooth structure at the coronal level. This finding is in accordance with the majority of laboratory (Akkayan 2004; Lima et al. 2009; da Silva et al. 2010) and clinical studies (Creugers et al. 2005; Ferrari, Cagidiaco, Grandini, et al. 2007; Cagidiaco, Garcia-Godoy, et al. 2008; Ferrari et al. 2012; Juloski, Fadda, et al. 2014) agreeing on the fact that more coronal structure positively affects the prognosis of ETT. Nevertheless, the Kaplan-Meier analysis suggests that the difference in survival between 2 degrees of hard tissue loss was statistically significant only between the 2 groups restored with SCs (Fig. 2B). Between the groups restored with FDPs, no difference in survival rates was revealed (Fig. 2C). Although the Cox regression analysis did not identify the type of restoration as a significant factor, based on the HR (1.695), it was noticed that risk of failure for FDPs was 1.6 times higher than for SCs placed on ETT restored with fiber posts. Besides, the survival curve of teeth with SCs on teeth with $>50 \%$ coronal structure showed significantly better results compared to that of FDPs also on teeth with $>50 \%$ coronal structure (Fig. 2D). On the other hand, on teeth with $<50 \%$ of residual structure, both SCs and FDPs performed similarly (Fig. 2G). Taking into account the above-mentioned facts, it could be concluded that besides the amount of tooth structure loss, the type of the final restoration is also an important issue when prognosis of the ETT restored with fiber posts is estimated. In particular, the least predictable outcome could be expected when structurally compromised teeth are restored with FDPs. However, in the present study, only 1 of the abutments of 3- to 4-unit FDPs was endodontically treated and fiber post restored. Different results could be expected if the clinical situation was different and if more than 1 abutment needed endodontic treatment and fiber post placement. 
Table 2. Cumulative Survival Rates Recorded in Experimental Groups over an 84-mo Observation Period.

\begin{tabular}{|c|c|c|c|c|c|c|c|c|}
\hline \multirow{2}{*}{$\begin{array}{l}\text { Type of } \\
\text { Prosthetic } \\
\text { Restoration }\end{array}$} & \multirow{2}{*}{$\begin{array}{c}\text { Amount of } \\
\text { Residual } \\
\text { Coronal } \\
\text { Dentin }\end{array}$} & \multicolumn{7}{|c|}{ Cumulative Survival: No. (\%) of Teeth Failed } \\
\hline & & Baseline & $6 \mathrm{mo}$ & $12 \mathrm{mo}$ & $24 \mathrm{mo}$ & $36 \mathrm{mo}$ & $48 \mathrm{mo}$ & $84 \mathrm{mo}$ \\
\hline I. Single-unit & A. $>50 \%$ & $30 / 30(100)$ & 29/30 (96.6) & 29/30 (96.6) & 28/30 (93.3) & 28/30 (93.3) & $27 / 30(90.0)$ & $27 / 30(90.0)$ \\
\hline $\begin{array}{l}\text { PFM crown } \\
\text { (SC) }\end{array}$ & B. $<50 \%$ & $30 / 30(100)$ & $30 / 30(100)$ & $27 / 30(90.0)$ & $24 / 30(80.0)$ & $22 / 30(73.3)$ & $21 / 30(70.0)$ & $19 / 30(63.3)$ \\
\hline 2. 3- to 4-unit & A. $>50 \%$ & $30 / 30(100)$ & 29/30 (96.6) & $28 / 30(93.3)$ & $26 / 30(86.6)$ & 25/30 (83.3) & $23 / 30(76.6)$ & $20 / 30(66.7)$ \\
\hline PFM FDP & B. $<50 \%$ & 30/30 (100) & 29/30 (96.6) & 29/30 (96.6) & 27/30 (90.0) & 22/30 (73.3) & 19/30 (63.3) & $17 / 30(56.7)$ \\
\hline
\end{tabular}

FDP, fixed dental prosthesis; PFM, porcelain fused to metal; SC, single crown.

Table 3. Distribution of Failure Modes among the Groups Observed after 84 mo of Clinical Service.

\begin{tabular}{|c|c|c|c|c|c|}
\hline \multirow{2}{*}{$\begin{array}{l}\text { Type of Prosthetic } \\
\text { Restoration }\end{array}$} & \multirow{2}{*}{$\begin{array}{l}\text { Amount of Residual } \\
\text { Coronal Dentin }\end{array}$} & \multicolumn{4}{|c|}{ Type of Failure, No. (\%) of Teeth Failed } \\
\hline & & PAL & PoDe & PoFr & RoFr \\
\hline \multirow{2}{*}{$\begin{array}{l}\text { I. Single-unit PFM crown } \\
\text { (SC) }\end{array}$} & A. $>50 \%$ & $2(6.6)$ & $0(0)$ & I (3.3) & $0(0)$ \\
\hline & B. $<50 \%$ & $4(13.3)$ & $4(13.3)$ & $\mathrm{I}(3.3)$ & $4(13.3)$ \\
\hline \multirow[t]{2}{*}{ 2. 3- to 4-unit PFM FDP } & A. $>50 \%$ & $4(13.3)$ & $4(13.3)$ & $0(0)$ & $5(16.6)$ \\
\hline & B. $<50 \%$ & $5(16.6)$ & $5(16.6)$ & $0(0)$ & $7(23.3)$ \\
\hline \multicolumn{2}{|l|}{ Total No. (\%) of teeth failed } & $15(12.5)$ & $13(10.8)$ & $2(1.6)$ & $16(13.3)$ \\
\hline
\end{tabular}

FDP, fixed dental prosthesis; PAL, periapical lesion; PFM, porcelain fused to metal; PoDe, post debonding; PoFr, post fracture; RoFr, root fracture; SC, single crown.

Moreover, only 1 previous study (Juloski, Fadda, et al. 2014), in addition to the present one, evaluated the amount of coronal tooth structure after the abutment preparation. All clinical studies published in recent years (Ferrari, Cagidiaco, Goracci, et al. 2007; Ferrari, Cagidiaco, Grandini, et al. 2007; Mannocci et al. 2002; Monticelli et al. 2003; Naumann, Blankenstein, Kiessling, et al. 2005; Schmitter et al. 2011; Zicari et al. 2011; Ferrari et al. 2012) assessed the residual tooth structure before the abutment preparation, which may have led to overestimation of the amount of tissues actually remaining at the coronal level. In 1 study, the teeth were categorized according to the expected dentin height after tooth preparation, which in fact represented a prediction made by the operator (Creugers et al. 2005). Therefore, to obtain more dependable information on the importance of the amount of coronal dentin and ferrule effect on clinical performance of ETT, it would be advisable to perform the calculation of the remaining tooth structure after the abutment preparation in future clinical studies.

Furthermore, resin cement with high filler content suitable for core buildup and fiber post luting was used in the present study, as it simplifies the clinical procedures and results in more mechanically homogeneous restorations (Boschian Pest et al. 2002). It may be presumed that enhanced mechanical properties of investigated core material (i.e., modulus of elasticity and fracture toughness) and the adhesion achieved by the bonding system employed were related to the outcomes recorded in this study. Hence, it could be speculated that the choice of a different combination of materials could have led to different results.

Regarding the type of failure, root fractures were observed (except in group 1A) for the first time after $3 \mathrm{y}$ of clinical service, with a higher rate in the last few years, which could be due to the deterioration of the adhesive interface or cumulative mechanical stress. It was previously confirmed that higher incidence of failures was recorded as the observation time increased (Creugers et al. 2005; Ferrari, Cagidiaco, Grandini, et al. 2007; Cagidiaco, Garcia-Godoy, et al. 2008; Ferrari et al. 2012). Throughout 7 y of clinical service, 4 teeth (13.3\%) were extracted in group $1 \mathrm{~B}, 5$ teeth $(16.7 \%)$ in group $2 \mathrm{~A}$, and 7 teeth $(23.3 \%)$ in group 2B. Higher occurrence of root fractures among teeth restored with FDPs, especially those with less preserved coronal structure, could probably be due to the particular biomechanical loading and dissipation of the occlusal forces on the restoration and the abutment teeth. Specifically, it is assumed that under occlusal load, the healthy abutments remained stable, while debonding of the restoration on the endodontically treated abutment caused a wedge and/or lever effect of the fiber post, which, regardless of its low modulus of elasticity, finally led to the fracture of the root. Among the other failure modes, the most common type of failure was periapical lesion (12.5\%), followed by post debonding (10.83\%). These results confirm previous findings (Cagidiaco, Goracci, et al. 2008; Ploumaki et al. 2013; Sorrentino et al. 2016). Post fractures were noticed only in 1 tooth from group $1 \mathrm{~A}$ and 1 tooth from group 1B. In contrast to this finding, fiber post fractures were reported as a frequent type of failure (Naumann, Blankenstein, and Dietrich 2005). The distribution of failure modes among the groups is reported in Table 3. However, all other failures beside the root fracture were considered favorable, and teeth could be restored in the same manner as described previously and remained in clinical service.

The results of the present study are in disagreement with previously reported higher failure rates for SCs and combined fixed-removable dental prostheses compared to failure rates of FDPs (Naumann, Blankenstein, Kiessling, et al. 2005). However, 
A Survival Functions (Log Rank test, $\left.\mathrm{p}=\mathbf{0 . 0 4 8}{ }^{*}\right)$

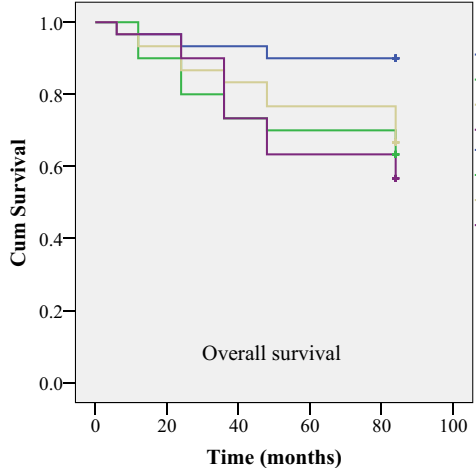

C Survival Functions (Log Rank test, $\mathbf{p}=\mathbf{0 . 4 3 3 )}$

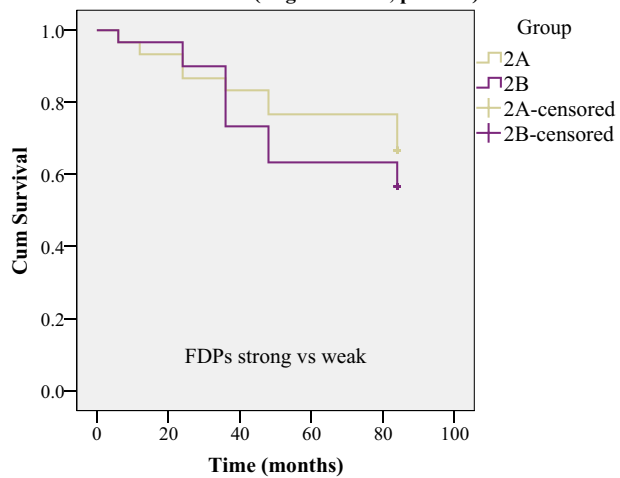

E Survival Functions (Log Rank test, $\mathbf{p}=\mathbf{0 . 7 2 5}$ )

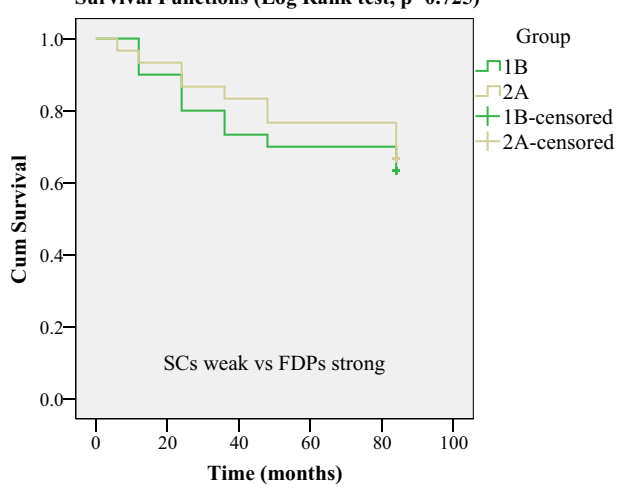

B Survival Functions (Long Rank test, $\mathrm{p}=\mathbf{0 . 0 1 7 *}$ )

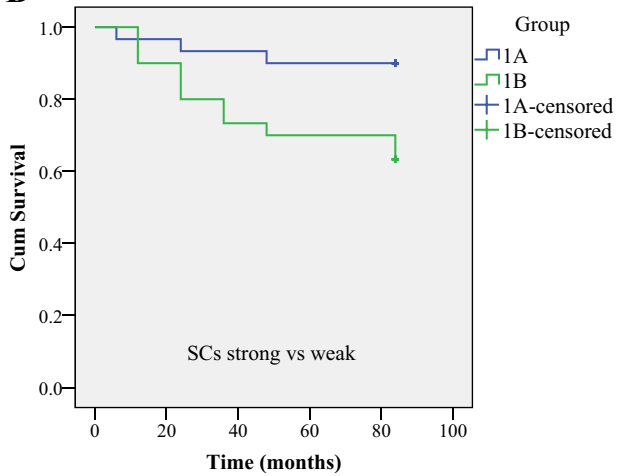

D Survival Functions (Log Rank test, $\mathrm{p}=\mathbf{0 . 0 3 5 *})$

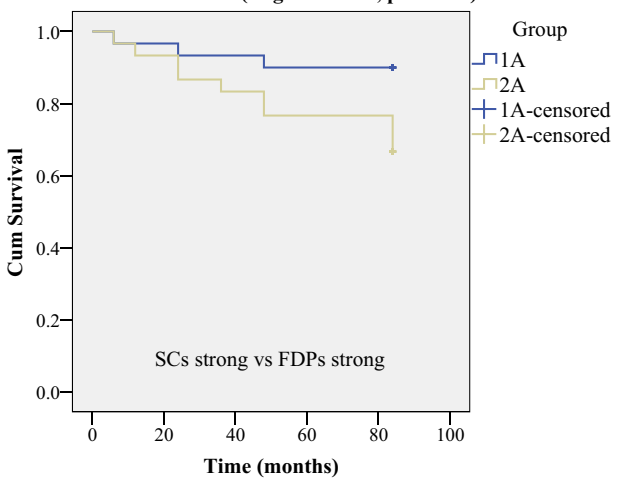

F Survival Functions (Log Rank test, $\mathrm{p}=\mathbf{0 . 0 0 5}$ *)

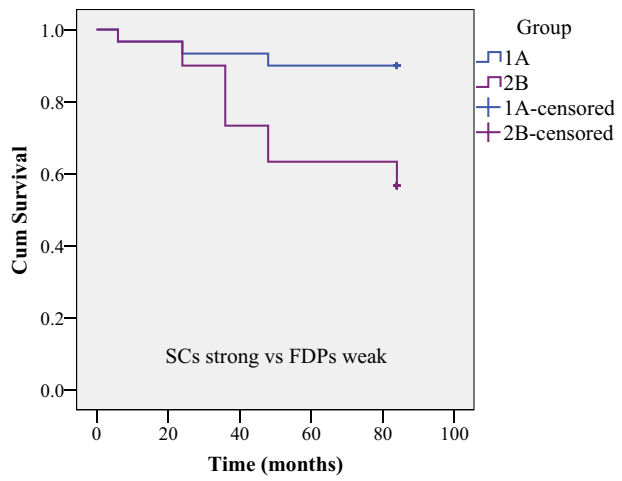

G Survival Functions (Log Rank test, $p=0.724)$

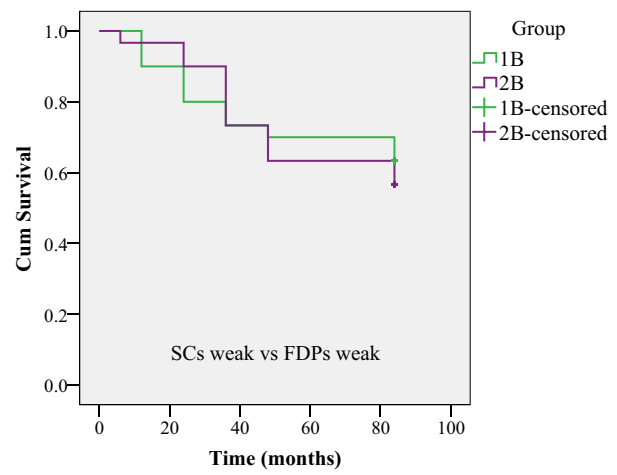

Figure 2. Kaplan-Meier survival plots (log-rank test, $P<0.05$ ). (A) Overall survival. (B) SCs strong versus weak. (C) FDPs strong versus weak. (D) SCs strong versus FDPs strong. (E) SCs weak versus FDPs strong. (F) SCs strong versus FDPs weak. (G) SCs weak versus FDPs weak. FDP, fixed dental prosthesis; SC, single crown. 
those are the results of a prospective cohort study performed on different types of teeth and different types of post on a relatively small sample size and small number of failures. In addition, the same study reported that anterior teeth had a 3 times higher failure rate than posterior teeth. Therefore, it cannot be extrapolated that the results of this study can be similar in anterior teeth, since they are exposed to higher horizontal forces causing tension stress during lateral and protrusive movements compared to more perpendicular compressive forces acting on posterior teeth. Since the maxillary anterior regions could be considered highrisk areas for failures (Torbjorner and Fransson 2004; Naumann, Blankenstein, Kiessling, et al. 2005; Naumann et al. 2008; Schmitter et al. 2011), further similar clinical studies evaluating the performance of ETT in the anterior region restored with fiber posts are desirable.

The following limitations could have influenced the present study: there was a limited number of patients, only teeth with no periodontal disease and no parafunctions were included in the study, the clinical performance of 3- versus 4-unit FDPs was not analyzed, a priori sample size calculation was omitted, and only posterior teeth with limited excursion and limited exposure to horizontal forces compared to anterior teeth were taken into consideration. The potential control group that could have been represented by ETT restored without fiber posts was not included in the present clinical trial, as scientific evidence exists that placement of prefabricated fiber posts significantly contributes to the survival of ETT and that restoring teeth without fiber posts increased the risk of failure (Ferrari, Cagidiaco, Grandini, et al. 2007; Cagidiaco, Garcia-Godoy, et al. 2008; Ferrari et al. 2012). Taking into account the high risk of a negative outcome of such kind of treatment, it was not considered ethical to include a control group of teeth without fiber post restorations.

In conclusion, over a 7-y observation period, the clinical performance of endodontically treated and fiber post-restored teeth with SCs and FDPs was significantly affected by the degree of hard tissue loss. A higher degree of hard tissue loss increased the risk of failure, and a less predictable clinical outcome could be expected when teeth with an insufficient coronal structure are restored with either FDPs or SCs.

\section{Author Contributions}

M. Ferrari, contributed to conception, design, data analysis, drafted and critically revised the manuscript; R. Sorrentino, contributed to conception, design, data analysis, critically revised the manuscript; J. Juloski, contributed to conception, design, and data analysis, drafted and critically revised the manuscript; S. Grandini, M. Carrabba, N. Discepoli, E. Ferrari Cagidiaco, contributed to conception and design, critically revised the manuscript. All authors gave final approval and agree to be accountable for all aspects of the work.

\section{Acknowledgments}

The authors received no financial support and declare no potential conflicts of interest with respect to the authorship and/or publication of this article.

\section{References}

Akkayan B. 2004. An in vitro study evaluating the effect of ferrule length on fracture resistance of endodontically treated teeth restored with fiberreinforced and zirconia dowel systems. J Prosthet Dent. 92(2):155-162.

Boschian Pest L, Cavalli G, Bertani P, Gagliani M. 2002. Adhesive postendodontic restorations with fiber posts: push-out tests and SEM observations. Dent Mater. 18(8):596-602.

Cagidiaco MC, Garcia-Godoy F, Vichi A, Grandini S, Goracci C, Ferrari M. 2008. Placement of fiber prefabricated or custom made posts affects the 3-year survival of endodontically treated premolars. Am J Dent. 21(3):179-184.

Cagidiaco MC, Goracci C, Garcia-Godoy F, Ferrari M. 2008. Clinical studies of fiber posts: a literature review. Int J Prosthodont. 21(4):328-336.

Creugers NH, Mentink AG, Fokkinga WA, Kreulen CM. 2005. 5-year followup of a prospective clinical study on various types of core restorations. Int J Prosthodont. 18(1):34-39.

da Silva NR, Raposo LH, Versluis A, Fernandes-Neto AJ, Soares CJ. 2010. The effect of post, core, crown type, and ferrule presence on the biomechanical behavior of endodontically treated bovine anterior teeth. J Prosthet Dent. 104(5):306-317.

Dietschi D, Duc O, Krejci I, Sadan A. 2008. Biomechanical considerations for the restoration of endodontically treated teeth: a systematic review of the literature, part II (evaluation of fatigue behavior, interfaces, and in vivo studies). Quintessence Int. 39(2):117-129.

Ferrari M, Cagidiaco MC, Goracci C, Vichi A, Mason PN, Radovic I, Tay F. 2007. Long-term retrospective study of the clinical performance of fiber posts. Am J Dent. 20(5):287-291.

Ferrari M, Cagidiaco MC, Grandini S, De Sanctis M, Goracci C. 2007. Post placement affects survival of endodontically treated premolars. J Dent Res. 86(8):729-734.

Ferrari M, Vichi A, Fadda GM, Cagidiaco MC, Tay FR, Breschi L, Polimeni A, Goracci C. 2012. A randomized controlled trial of endodontically treated and restored premolars. J Dent Res. 91(Suppl 7):72S-78S.

Goracci C, Ferrari M. 2011. Current perspectives on post systems: a literature review. Aust Dent J. 56 (Suppl 1):77-83.

Guldener KA, Lanzrein CL, Siegrist Guldener BE, Lang NP, Ramseier CA, Salvi GE. 2017. Long-term clinical outcomes of endodontically treated teeth restored with or without fiber post-retained single-unit restorations. J Endod. 43(2):188-193.

Jotkowitz A, Samet N. 2010. Rethinking ferrule - a new approach to an old dilemma. Br Dent J. 209(1):25-33.

Juloski J, Apicella D, Ferrari M. 2014. The effect of ferrule height on stress distribution within a tooth restored with fibre posts and ceramic crown: a finite element analysis. Dent Mater. 30(12):1304-1315.

Juloski J, Fadda GM, Monticelli F, Fajo-Pascual M, Goracci C, Ferrari M. 2014. Four-year survival of endodontically treated premolars restored with fiber posts. J Dent Res. 93(Suppl 7):52S-58S.

Juloski J, Radovic I, Goracci C, Vulicevic ZR, Ferrari M. 2012. Ferrule effect: a literature review. J Endod. 38(1):11-19.

Lima AF, Spazzin AO, Galafassi D, Correr-Sobrinho L, Carlini-Junior B. 2009. Influence of ferrule preparation with or without glass fiber post on fracture resistance of endodontically treated teeth. J Appl Oral Sci. 18(4):360-363.

Mancebo JC, Jimenez-Castellanos E, Canadas D. 2010. Effect of tooth type and ferrule on the survival of pulpless teeth restored with fiber posts: a 3-year clinical study. Am J Dent. 23(6):351-356.

Mannocci F, Bertelli E, Sherriff M, Watson TF, Ford TR. 2002. Three-year clinical comparison of survival of endodontically treated teeth restored with either full cast coverage or with direct composite restoration. J Prosthet Dent. 88(3):297-301.

Monticelli F, Grandini S, Goracci C, Ferrari M. 2003. Clinical behavior of translucent-fiber posts: a 2-year prospective study. Int J Prosthodont. 16(6):593-596.

Naumann M, Blankenstein F, Dietrich T. 2005. Survival of glass fibre reinforced composite post restorations after 2 years-an observational clinical study. J Dent. 33(4):305-312.

Naumann M, Blankenstein F, Kiessling S, Dietrich T. 2005. Risk factors for failure of glass fiber-reinforced composite post restorations: a prospective observational clinical study. Eur J Oral Sci. 113(6):519-524.

Naumann M, Reich S, Nothdurft FP, Beuer F, Schirrmeister JF, Dietrich T. 2008. Survival of glass fiber post restorations over 5 years. Am J Dent. 21(4):267-272.

Peroz I, Blankenstein F, Lange KP, Naumann M. 2005. Restoring endodontically treated teeth with posts and cores-a review. Quintessence Int. 36(9):737-746.

Ploumaki A, Bilkhair A, Tuna T, Stampf S, Strub JR. 2013. Success rates of prosthetic restorations on endodontically treated teeth; a systematic review after 6 years. J Oral Rehabil. 40(8):618-630. 
Schmitter M, Hamadi K, Rammelsberg P. 2011. Survival of two post systems - five-year results of a randomized clinical trial. Quintessence Int. 42(10):843-850.

Schmitter M, Rammelsberg P, Gabbert O, Ohlmann B. 2007. Influence of clinical baseline findings on the survival of 2 post systems: a randomized clinical trial. Int J Prosthodont. 20(2):173-178.

Schwartz RS, Robbins JW. 2004. Post placement and restoration of endodontically treated teeth: a literature review. J Endod. 30(5):289-301.

Signore A, Kaitsas V, Ravera G, Angiero F, Benedicenti S. 2011. Clinical evaluation of an oval-shaped prefabricated glass fiber post in endodontically treated premolars presenting an oval root canal cross-section: a retrospective cohort study. Int J Prosthodont. 24(3):255-263.

Sorrentino R, Di Mauro MI, Ferrari M, Leone R, Zarone F. 2016. Complications of endodontically treated teeth restored with fiber posts and single crowns or fixed dental prostheses - a systematic review. Clin Oral Investig. 20(7):1449-1457.
Stankiewicz NR, Wilson PR. 2002. The ferrule effect: a literature review. Int Endod J. 35(7):575-581.

Sterzenbach G, Franke A, Naumann M. 2012. Rigid versus flexible dentine-like endodontic posts - clinical testing of a biomechanical concept: seven-year results of a randomized controlled clinical pilot trial on endodontically treated abutment teeth with severe hard tissue loss. J Endod. 38(12):1557-1563.

Tay FR, Pashley DH. 2007. Monoblocks in root canals: a hypothetical or a tangible goal. J Endod. 33(4):391-398.

Torbjorner A, Fransson B. 2004. Biomechanical aspects of prosthetic treatment of structurally compromised teeth. Int J Prosthodont. 17(2):135-141.

Zicari F, Van Meerbeek B, Debels E, Lesaffre E, Naert I. 2011. An up to 3-year controlled clinical trial comparing the outcome of glass fiber posts and composite cores with gold alloy-based posts and cores for the restoration of endodontically treated teeth. Int J Prosthodont. 24(4):363-372. 